\title{
White Champaka: The Pattern Design Dimension to the Applying of the Aromatherapy Seat Cushion
}

\author{
Rosjana Chandhasa ${ }^{1}$, Jong Boonpracha ${ }^{1}$, Somsakul Jerasilp ${ }^{1} \&$ Palang Wongtanasuporn ${ }^{1}$ \\ ${ }^{1}$ Faculty of Industrial Technology, Department of Industrial Design, Suan Sunandha Rajabhat University, \\ Thailand \\ Correspondence: Rosjana Chandhasa. Tel: 66-955-181-285. E-mail: rosjana.ch@ssru.ac.th
}

Received: November 29, 2017

Accepted: February 9, 2018

Online Published: February 26, 2018

doi:10.5539/ass.v14n3p14

URL: https://doi.org/10.5539/ass.v14n3p14

\begin{abstract}
The objectives of this research is to study the denotation and the culture of the white champaka conduct to the pattern design as well as to evaluate the pattern design result for use with the aromatherapy seat cushion. The research process, the researcher had selected the mixed method research begin by studying and searching the information with qualitative research in carrying out the investigation of the white champaka cultural background and then use a quantitative research to evaluate the pattern design accomplishment that conduct to the seat cushion usability. Scope of research area was the white champaka in Bangkok, samples as 3 experts and 100 consumers, the research used the accidental sampling at the domestic exhibition center, which was shown on Baanlaesuan Event for the purpose of getting satisfaction towards the seat cushion product design. Research instruments as follows, searching for literature review, in depth interview as well as using the questionnaire and the assessment forms.

The investigation of the white champaka cultural background results revealed about the holy culture, Thai herbal incense culture, the emblazonment and the flower arrangement culture. The researcher decided for Thai herbal perfume culture by bringing the dried flowers, the dried herbal compression ball that contain various herb ingredients such as Turmeric, Kiffir Lime, Citronella grass, Menthol, Thao En On, Cassumunar ginger, Salt, Tamarind, and Eucalyptus leaves that were used as the seat cushion component through the aroma therapy concept. The pattern design inspired by the white champaka, the fabric pattern type 1: pattern design with Realistic technique that the top rank by the average at 4.80 with the highest optimal satisfaction utilized as the aroma seat cushion production. The satisfaction assessment from 100 consumers toward the seat cushion product in terms of beauty as well as the composition of pattern and color: their opinion affected in terms of pattern had a high level with appropriateness utilized as the seat cushion product, their opinion affected in terms of function showed the usability of the seat cushion product, the durability, the quality, the suitability in usage and the suitability for the seat cushion product had a high level, the opinion affected in terms of marketing found the product could be an interesting attraction from consumers, The product could be promoted sales by themselves and the appropriateness of cost and size had a medium level which related to the assessment of the consumers and the specialists about the pattern design could conduct to the seat cushion product development as well as production and distribution with standardization and they could be responsible the target group that satisfied with seating therapy as a result the usability when seating likes the herbal massage, furthermore the aroma therapy could be also decreased stress in terms of marketing that found from consumers
\end{abstract}

Keywords: White Champaka, pattern design, Aroma Therapy Seat Cushion

\section{Introduction}

In the former times, the growth means being flourish and exuberance liken to the tree growth when grow up, afterwards fruitfulness which fantastic. In the former time of flower have been a pleasing scent that having perception through 2 sense sensory, namely, the eyes sense; the vision of admiring the beauty, the civilization as well as the complete within the former natural times, the nose sense; the sweet smell of the fascinating flower with hiding something secret of charming into the flower, the sweet smell of flower have been the former times that if everyone have kept in touch, they would have impressed on the esthetics of the creative appearance nature. Many blossom flowers had been brought to utilization as daily life since ancient time turns into the country custom nowadays such as using the flower at the monk ordination ceremony, a gift for visiting the patient, for the 
lover, the housewarming ceremony, home decoration or even using in the funeral ceremony, besides, people in old time had used the flower as the medicine to heal the illnesses and also used to prepare for food. In addition, the former times in the present have found people still searching for happiness, enjoyableness, a natural beauty, so the beautiful flowers had been arranged to decorate on the art with correctly that affected the beauty increasing moreover. The importance of selecting the white champaka in to the pattern design of seat cushion product that make us known the value and the meaning of Thai flowers. Therefore, researcher had realized on Thai conservation and the cultural background for the purpose of students, teachers and general public getting flowers acknowledge that used at the institute which express Thai traditional.

According to aromatherapy can be defined as the art and science of utilizing extracted aromatic essence oil from plants for physical treatment and emotional health, reducing pain, improving mood, keep calming and relaxing, controlling some hormone balance secretion, thus the aromatherapy could be utilized for treatment about mind and spirits. Presently, there are increasing of a new business related to health also as a result of people getting emphasized about the alternative medicine by they had they had used the practice of natural treatment for relieving pain slightly instead of checking up with doctor. On account of avoiding from the cumulative chemical medicine residual in the body, thereby the aroma essence oil business have been a future kudos business that could be getting the extremely income to the entrepreneurs as well as this business has trended to be growing continuously and consequently, there would have given the acknowledge and the benefits of the essential oil for health and the aroma therapy science with correctly in order to get the perceiving and understanding for widely because the essential oil has many benefits, even if using as the wrong direction, the essential oil without quality and producing from chemical synthetic not a natural oil extracted that affected to harmful for consumer health. When feeling stressed, many people would have found the way to stress treatment with "aroma", thus, the benefits of sweet smell not only to make a fresh feeling, but also to relax, stress relief, including a certain plain relieve.

Using the aromatic from plant extracted to essential oil for "treatment" as known as aromatherapy that has been used for over6,000 of years with the evidence that it was employed using both in the ceremony and for relaxing by the Ancient Egyptians then the aroma essence oil was used for therapy by Greek and utilizing up till now. Although the essential oil had not used only in the West Country but the East Countries such as India had found the evidence for 3,000 years ago that the essential oil was used for beauty, relaxation and therapy, at the same time of Egypt, China had the account by utilizing extracted aromatic essential oil from herbal plants and the various aromas were extracted from variety plants more than 300 plants. As the result of the aromatic essence extracted having benefits for a health body and mind, when the body had perceived the essential oil that affected to a system of the human body of controlling nerve system and secretes hormones, the perceived aroma would be stimulating to part of brain, which is in charge of emotion, therefore there could be handle the emotion from each with its own properties function

Presently, the aromatherapy seat cushion product development are very important to conduce consumer keep in touch of the beautiful white champaka, when have sat on the cushion it would be making the white champaka's aroma of the white champaka. The essential oil extracted from the white champaka was conducted to make the incense as well as contained into the seat cushion, each essential oil has different properties such as healing allergenic, antimicrobial, in addition, each scent has been making different emotion, such as relaxation, calm or refreshment that appropriateness for the present age with hustle and high competition that influenced people have felt more stressful. The exploring result of Institute for Research and Academic Service Assumption University (AU Poll) revealed the exploratory research about the Thai Stress index: the case study of people in Bangkok and Metropolises with total 2,000 samples, the result found Metropolitans in upcountry having a higher stressed (with average stress $=2.24$ ) than in Bangkok (average stress $=2.11$ ), both of them had the same stress seeing at the study was the highest stress, as the following, work, economy/finance, respectively, there was different between this survey finding (October, 2016) and the survey finding at the last time (August, 2016) since the metropolis in Bangkok was stress than in upcountry. Therefore, the aromatherapy seat cushion product design should assist people relieve stress by the scent of aromatherapy inside the cushion.

\section{Research Objectives}

1. To study the definition and the culture of White champaka conduct to the pattern design.

2. To evaluate the pattern design result with applied to the aromatherapy seat cushion design. 


\section{Research Conceptual Framework}

The White champaka conceptual framework conduct to the pattern design and the seat cushion product.

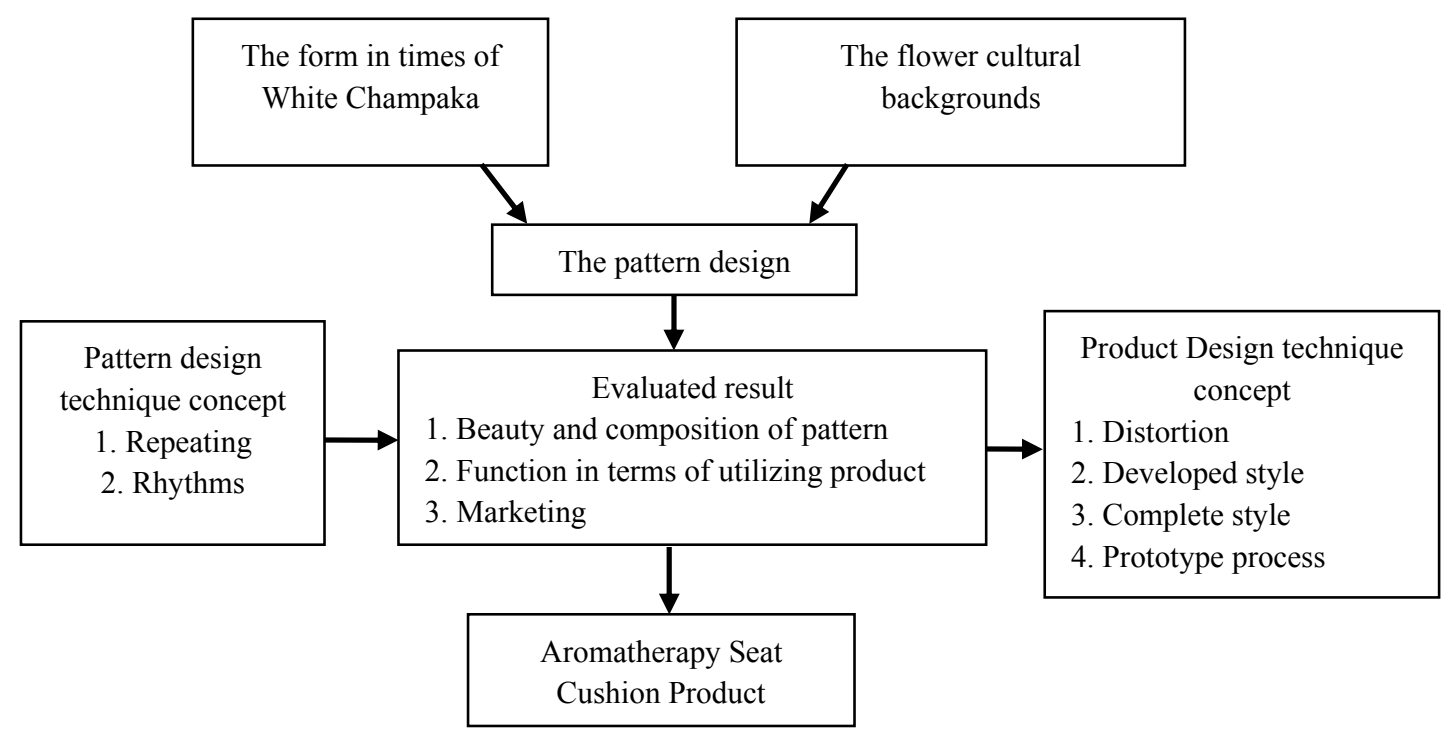

Figure 1. Research Conceptual Framework

\section{Research Methodology}

This research had been using the mixed method by researcher, begun to study and searching the information with a qualitative research, then used the quantitative research to evaluate the result of pattern design utilized in the aromatherapy seat cushion product.

\subsection{Scope of Research}

The delimitation of this research included:

(1) Area scope and content: the white champaka only in Bangkok and the flower culture related to the holy culture, the incense culture as well as the flower arrangement culture and the emblazonment.

(2) Sampling method: the printing fabric store only in Bangkok by using a purposive sampling method which totally 10 people for collecting the type of printing fabric data system, the pattern as well as the seat cushion product production.

(3) The 3 product design experts which the specialists in the product design field and having experiences in related product at least 10 years were selected in order to consult about a design result, adjust the style in accordance with the objective determination as well as the design evaluation

(4) Consumer sampling: the sampling group was 100 people by using the accidental sampling method at the domestic exhibition center which was shown of Baanlaesuanfair Event.

\subsection{Research Instrument}

(1) Investigating from the document and literature review related within the former times and the white champaka cultural background.

(2) Using an in-depth interview method including a participant observation from distributors at the domestic exhibition center which was shown of Baanlaesuanfair Event

(3) Performing in pattern design by using in the former times as well as the white champaka cultural background, taking the illustrators to present and utilizing the information from the distributors so as to communicate in the same direction.

(4) Using the evaluations which were the opinion results from the consumer and the experts towards the style of seat cushion product model in terms of the beauty and pattern composition, in terms of function related with the usability of seat cushion product and the marketing. 


\section{Data Collection and Data Analysis}

\section{Research Step 1: Preparation and Collecting Data}

(1) The conference, to explain the activity description, preparation and bring understanding correspondingly accompany with the printing fabric's entrepreneur in order to conducted the white champaka printing on fabric including pattern arrangement that affected to printing

(2) Investigation of the documents and a review literature with be concerned, analysis of the former times of the white champaka as well as the cultural background for applying to the pattern design

(3) Investigation and analysis type of product to develop as a seat cushion product by using the questionnaire, the evaluation and observation with the target group to study the problems, resolution and market trends.

Research Step 2: Investigation and analysis in the former times and the cultural background of white champaka in the pattern design.

(1) Researcher had found the cultural background of white champaka with be related, namely, the incense culture of Thai as well as the arrangement flower culture and the emblazonment, that could be concluded:

1. The incense culture of Thai, according to a treatment by the scent or the aromatherapy having become popular and throughout around the world. For each social would have the folk wisdom of using the flower, the perfume, the incense and the various aromatic herbs in the daily life such as the belief, the religion, including healing illness for the long time, around in some from for a thousand of years. In Thai society, the ancestors had been learning from nature and having created many incenses to use in daily life such as, Thai perfume, Num Prung, perfumed powder or the hanging on Thai with made from fresh flower arrangement in order to pay respect the monk as well as use in the religious ceremony. The aromatic flowers that commonly using were jasmine, bullet wood, iron wood, Sara phi, ylang-ylang/perfume tree, screw pine, butterfly bush, white champaka, orange champaka, Shorea, Nom-maw tree, sandalwood, etc. Besides, being used the aroma benefit in everyday life, there are a various Thai flowers which working as the medicine's properties such as the pollens from 5 flowers namely, jasmine bullet wood, iron wood, Sara phi and lotus that also could able utilized to Ya Hom or Ya Lom ingredients (cordial) in order to heart maintenance, honeysuckle flower has the enteritis healing effect especially the bacillary dysentery, Ros-Su-Khon flower which white having heart maintenance effect, Maliwan has use for nourishing pregnancy, heart maintenance, healing the rise in temperature, white ginger use as the gargle in order to healing tonsil inflammatory, the white ginger juice could use as the drug wound, gardenia flower utilized the leaf pounded as the plaster which can relieve the headache, sprain, bile maintenance, blood nourishment and bronchodilator, the white champaka can use by drinking the water boiling with the dried leaf with water that can help the cough mixture and bronchitis, prostate is and leucorrhea.

2. The flower arrangement culture and emblazonment was found, in the reign of the King Rama 5 had commonly been using flowers in the ceremonies, therefore, the ladies at the court often arranged the competitive flower emblazonment for use in the ceremonies, constantly. At that time the Princess of Samornrat, the King Rama 5's sister who has taken the position of the director-general lady in the court having a comprehension about flower weaving emblazonment, consequently, the reputation of flower arrangement being celebrated famous until nowadays. The Princess of Samornrat was an eldest sister of the King Rama 5 accompanied by the director-general in the court thus being able to command all the lords arranging the flower for emblazonment the throne with the holy thread in the ceremonies, including the doors and the windows in the palaces. Moreover, the Princess of Samornrat could be always finding the flowers to use in the ceremonies, even if arranging the flower with traditional style, arranging the flowers were applied to the new style, for in stancein the pass. The traditional trelliswork was covered with the white fabric using the weaving net or swags to decorate with the same style, repeatedly such as the platform decorated with garland with tassels, inverse tassels, atilt tassels and Chinese tassels, although, the Prince of Samornrat was creating a trelliswork by painting white color as well as having created a beautiful flower with a different style such as the hanging modified as the bag flowers style, the platform modifies as the Viman Pra Inn style and Viman Tan style. Until now the creative flower designs have been keeping forward with greatly.

During the Queen Mom had a famous of weaving the garland, the Princess of Suthasineenath the Royal Sort of the King Rama 5 had a famous of weaving the garland to various net patterns shaggy. The lords in this palace had woven both original styles and also applied to other styles including alternate the color with beautifully. The flower arrangement with other style had been developing to various styles, nevertheless, only the weaving net pattern had been taken note in the history which actually in that time had many craftsmen with various skills that dedicated work for the lords on a regular basis but some people who known the writer were not interesting 
neither thinking that were the most important, they did not take a note in order to do the honors as the worship of generation. In addition, the craftsmen had been working with the intention and their best for the work creation were beautiful and delightful including for the lord had appreciated that made them gladness, there had not the evidence or taken the note about the occurring. Observing mostly the originators as well as the famous persons were the ladies in the court and the government officers owning to the palace had been the training place for women, so that the lords, the government officers and the barons had desired their daughters being competent in the art and science including the decorum therefore, sending their daughter were living with their closed her/his highness. When having the ceremonies, all her/his highness or the lords would arrange the flower for competition and offered to His Majesty King or the throne wrests binding string emblazonment also organized the governors working as their dexterous together with training the children such as picking up the flower stalk or petal that they could be done, then practicing the flower weaved technique for simple basis, folding the petal and sending to senior and weaving the net pattern garland or flower arrangement with lotus shape, keep training as their best complementary by receiving the trust then they would be taught the flower arrangement at the advance stage. The study was in the same direction of training by having their best skills. For knowing what things were beautiful or was not, consideration of the experiences, a smart intelligent, including having the art of flower arrangement skills, when the parent had found that their daughters getting the flower arrangement with technique skills, including as known the regulation of customs, they would tell his/her highness to get their daughter back at home and getting married, when having the ceremonies like the wedding, the ordaining, the tonsure, the making merit, the funeral or the worship ceremonies on Bucha Puja Day, Visakha Bucha Day and Magha Bucha Day, they would have arranged the flower showing a technique skill as well as advertised their daughter received a good education form the palace. The growing of flower arrangement had been well known throughout the country; however, the government officers in the court of the Royal Household still have the reputation technique skills as well as the knowledge of flower technician all the time.

(3) From finding, the flower common name: White Champaka, White sandalwood, White Jade Orchid tree, the scientific name: Michelia alba Dc. (syn. Michelia longifolia var. racemosa Blume), belonging to the Magnolia family (MAGNOLIACEAE), the local name of herbal white champaka: Chumpee (the Northern) etc. Description: the white champaka tree origin is the Southeast Asia (although the exact origin uncertain, it considers to the Southern China, Malaysia and Indonesia), classification of the species includes about 50 species with a perennial tree, a middle timber size and higher than the orange champaka, 20-50 meters high, a dark brown trunk is cracked with a lot of chicks, the branch has grey hairs with being brittle and easily broken, the propagation is done by grafting or seeds, the leaf characteristic is a monocot, green leaf, top of the leaf is round, the apical leaf is acute, leaf edge is smooth, thickness and large leaf with $8 \mathrm{~cm}$ wide and $20 \mathrm{~cm}$. long, the blossom is a single, scent, as white as ivory, the petals are overlapping about 8-10 petals, taped than the orange champaka, 2 inch long, the middle of the blossom had some pollen as a little round stick, the apex is resembled a little corncob, blooming throughout the year, the fruit characteristic is a cluster when ripen will be dying and cracked, resemble in oval shape, distorted a bit, ripen become red, 4 black seeds inside, the white champaka benefits: as the flowerer in the garden tree which blooming all the year, to make a bouquet hanging with the garland for sale, to pay respect the Buddha, use to produce for flavoring cosmetic, to make fragrant cloth by dried together with the flower as well as the wood can be used as the furniture.

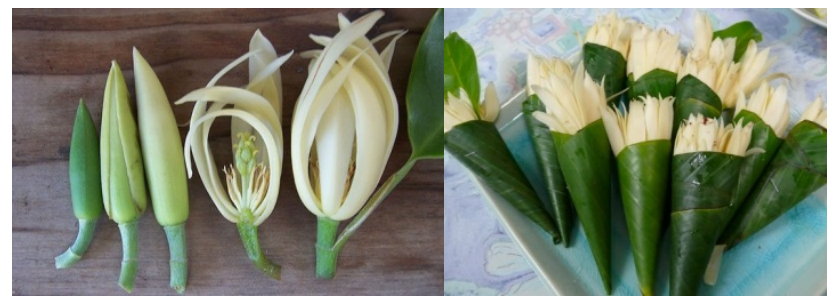

Figure 2. The white champaka characteristic and banana leaf cone for paying respect the Buddha

Research stage 3: The experiment of the pattern design operation inspired by the white champaka conduct to the fabric pattern design, at the follows:

1. Researcher had designed pattern with the Realistic style by drawing the natural swaying white champaka in order to making a movement. Researcher had used the principle of pattern design composition with a repeating technique as well as a rhythm technique to compose the pattern in order to make the highlight with interesting and using the white champaka's the yellow-pastel color as the background, using the blue and the dark yellow 
represent as the white champaka color to make the airy and comfortable feeling by using 80 percentages of the cool color as well as 20 percentages of the red color which the line expressed the movement resembled in the white champaka start blooming, as shown in Figure3.

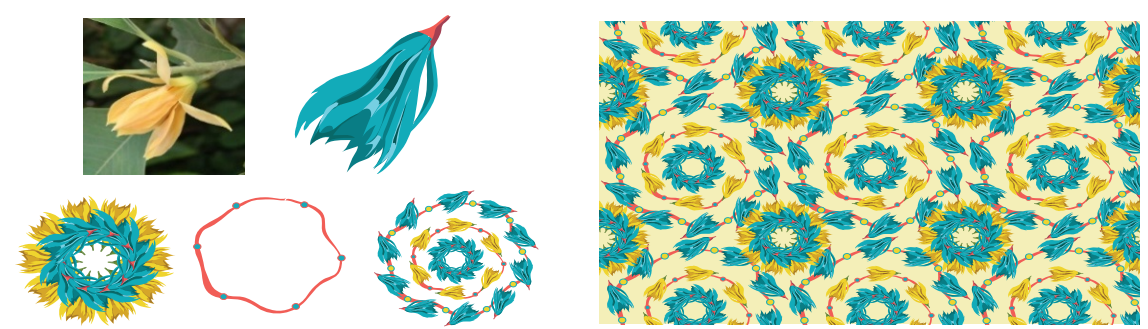

Figure 3. The pattern design works from the white champaka. Designed by Rosjana Chandhasa Pat.IP, No:1402003943

2. Researcher had designed pattern with Distortion style: the creative art work with distorted the realistic appearance by emphasizing the realistic style with less thought further emphasized on the art concept in order to communicate the beauty perceiving to understand with easily and rapidly. The creative visual art work with the distortion style that conducting visual elements utilized to the art work's composition by distorting the realistic scene according to the art concept in order to communicate the beauty perceiving to understand easily and rapidly by drawing the natural swaying white champaka in order for making a movement. Researcher had used the principle of pattern design composition with a repeating technique as well as a rhythm technique to compose the pattern for making an interesting highlight including using the white champaka's dark purple color as the background, an orange and a red represent as the white champaka color, to make the ardent feeling with 80 percentage of the warm tone color couple namely, the red and the orange color, including 20 percentage of the cool tone color such as the blue and the purple color, using the white color line in order to attract the white champaka distinctly.
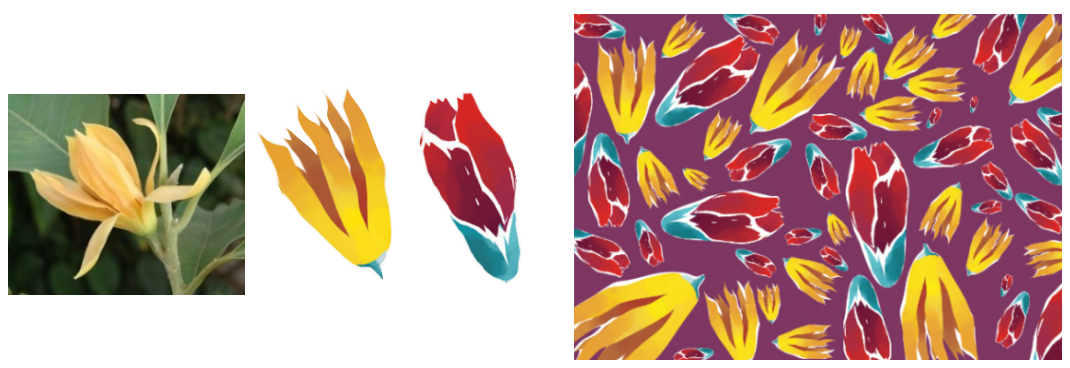

Figure 4. The pattern design works from the white champaka. Designed by Rosjana Chandhasa Pat.IP, No: 1502001013

3. Researcher had designed the pattern with Abstraction style: the creative artwork without the style and the realistic scene although focus on the artist feeling expression pass on the creative visual art work with the abstraction style that conducting the visual elements utilized in the art composition as well as urged the emotional feeling such as the enjoyment, the excitement, the fright, the sadness, being ardent, the love, as shown at Figure5.
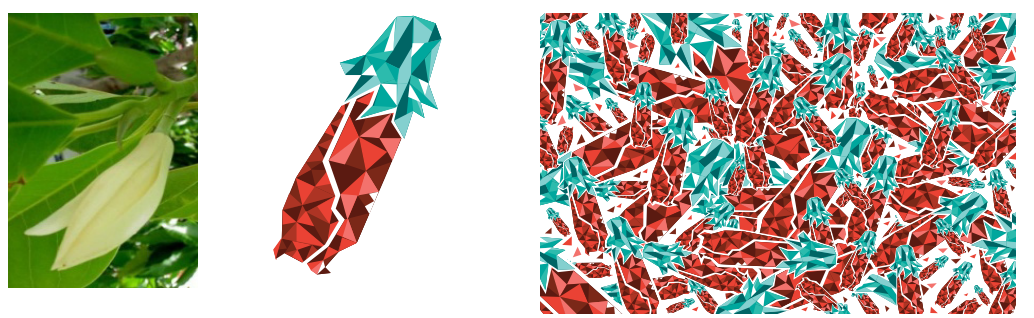

Figure 5. The pattern design works from the white champaka.Designed by Rosjana Chandhasa Pat.IP, No: 1502001006 


\section{Conclusion of Research Result}

6.1 The research result of conducting the white champaka had been an inspiration to fabric pattern design and conducing into the aromatherapy seat cushion product, result was as the follows:

Table 1. Analysis result the pattern design fabric from the white champaka design conduce to usability pattern $\mathrm{N}=3$ (The product design experts

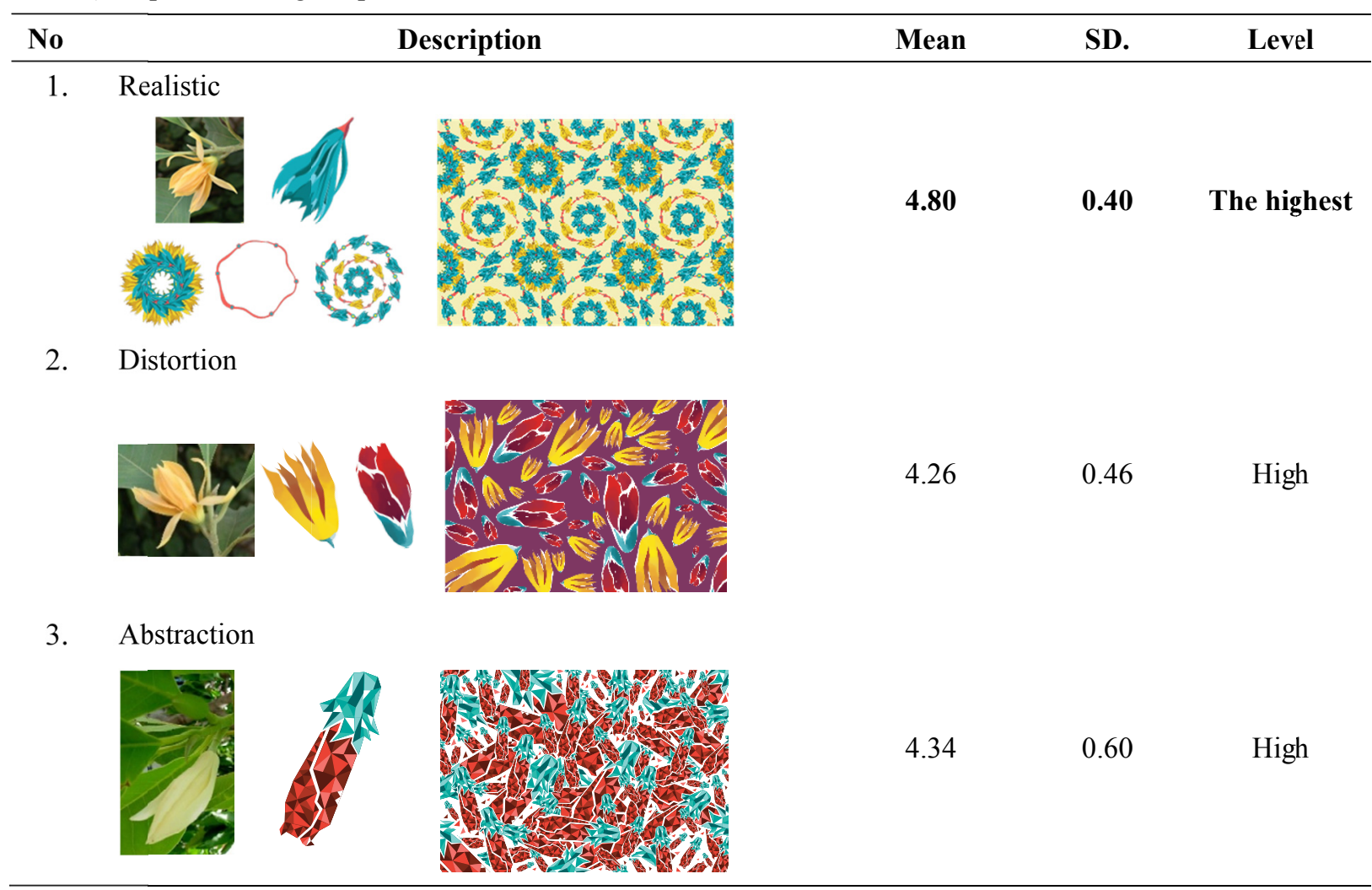

According to the Table 1, in conclusion, the analysis result of a fabric pattern design from the white champaka found the pattern design type 1: the pattern design with the realistic technique was the most optimal satisfaction for the aroma seat cushion production, as the followed the number $2^{\text {nd }}$, the fabric pattern design with the Abstraction technique had a high level of satisfaction and the number $3^{\text {rd }}$ the pattern design with Distortion technique had a high level of satisfaction.

6.2 The result of the aromatherapy seat cushion which researcher inspired from the white champaka with conducted the petals to use in seat cushion product design and seats design for seating in the circle for 5 seats or seating arrangement with others. Within the cushion, researcher had put the various dried flowers as well as the herbal plants brought to mix with the white champaka perfume for making fragrance, then containing within the seat cushion. In order that sitting could be scented the herbs, namely turmeric, kaffir lime rind, lemon grass, menthol, Thao En On, Cassumunar ginger, salt, tamarind and eucalyptus leaves, drying all herbs and contained within the cushion. This concept will make users stress relieved emotion; the fragrance will make fresh feeling.

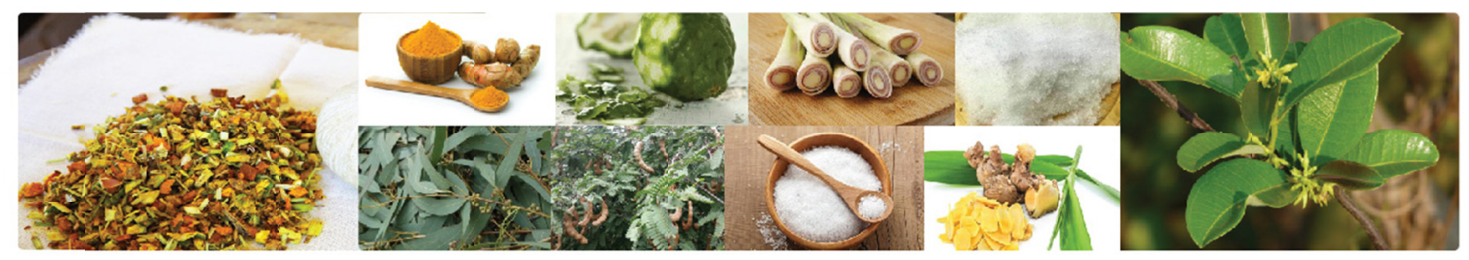

Figure 6. The incenses herbs for containing within the seat cushion 


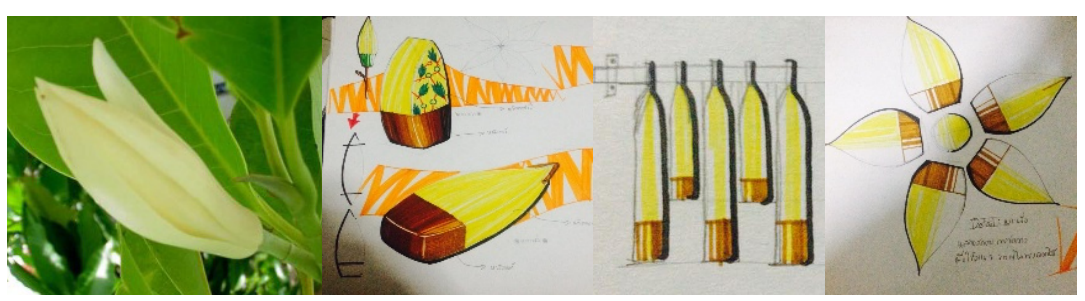

Figure 7. The seat cushion design sketch Designed by Rosjana Chandhasa

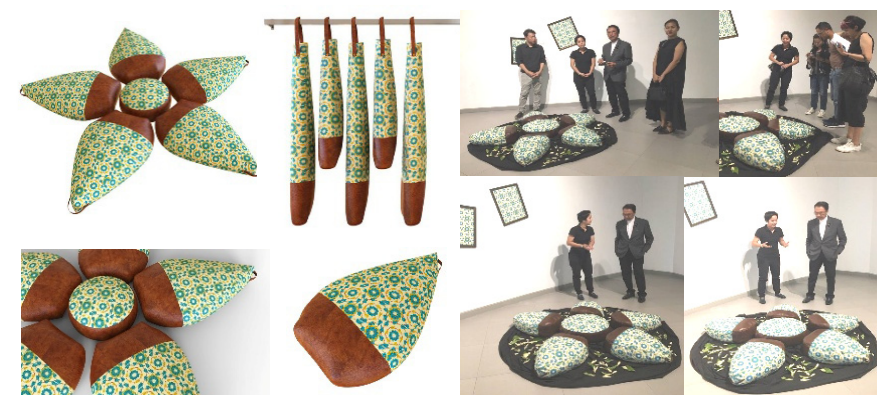

Figure 8 . The seat cushion design prototype and the blossom former of timesof the aroma cushion work exhibition show

Regards to the loop design in order to keep after used it by hanging which could be safe the area space, as shown in the picture.

\subsection{The Evaluation Result of the Seat Cushion Pattern Design}

The evaluation result of the seat cushion product, researcher used the assessment form in order to evaluate the satisfaction from 100 consumer and 3 experts in product field.

Table 2. The evaluation result of consumer satisfaction towards the seat cushion product $\mathrm{N}=100$

\begin{tabular}{|c|c|c|c|c|}
\hline Rank & Description & Mean & S.D. & level \\
\hline \multicolumn{5}{|c|}{ 1. the beauty as well as composition of pattern } \\
\hline 1.1 & The beauty of composition arrangement & 3.57 & 1.17 & High \\
\hline 1.2 & The beauty of color and pattern & 3.49 & 1.07 & High \\
\hline \multirow[t]{2}{*}{1.3} & The beauty of pattern on the product & 3.50 & 1.09 & High \\
\hline & Total & 3.52 & 1.11 & High \\
\hline \multicolumn{5}{|c|}{ 2. The function of the usability of seat cushion product } \\
\hline 2.1 & The durability & 3.34 & 1.09 & Medium \\
\hline 2.2 & The quality & 3.52 & 1.12 & High \\
\hline 2.3 & The suitability size for usage & 3.45 & 1.08 & High \\
\hline \multirow[t]{2}{*}{2.4} & The suitability for the seat cushion product & 3.42 & 1.13 & High \\
\hline & Total & 3.43 & 1.10 & High \\
\hline \multicolumn{5}{|c|}{ 3. The marketing } \\
\hline 3.1 & the product could be an interesting attraction from consumer & 3.27 & 1.17 & Medium \\
\hline 3.2 & The product could be promoted sales by themselves & 3.40 & 1.17 & High \\
\hline 3.3 & The product could be convey to identity & 3.13 & 1.10 & Medium \\
\hline 3.4 & The appropriateness of cost and size & 3.23 & 1.14 & Medium \\
\hline \multicolumn{2}{|r|}{ Total } & 3.25 & 1.15 & Medium \\
\hline
\end{tabular}


As is presented in Table 2, the satisfaction assessment result from 100 consumer towards the seat cushion product in terms of beauty as well as the composition of pattern revealed that their opinion affected in terms of color and pattern was a high level with appropriate to conduct the pattern for usability, in terms of function of the usability of seat cushion product found their opinion affected in terms of durability, in terms of quality, in terms of suitability size for usage and in terms of suitability for the seat cushion product were a high level, their opinion affected in terms of market found that in terms of the product could be interesting attraction from consumer and the product could be promoted sales by themselves were a medium level.

Table 3. The evaluation result of consumer satisfaction towards the seat cushion product $\mathrm{N}=3$

\begin{tabular}{|c|c|c|c|c|}
\hline Rank & Description & Mean & S.D. & level \\
\hline \multicolumn{5}{|c|}{ 1. The beauty as well as composition of pattern } \\
\hline 1.1 & The beauty of composition arrangement & 4.00 & 1.00 & High \\
\hline 1.2 & The beauty of color and pattern & 4.33 & 1.15 & High \\
\hline \multirow[t]{2}{*}{1.3} & The beauty of pattern on the product & 4.66 & 0.57 & Highest \\
\hline & Total & 4.33 & 0.90 & High \\
\hline \multicolumn{5}{|c|}{ 2. The function of the usability of seat cushion product } \\
\hline 2.1 & The durability & 4.33 & 0.57 & High \\
\hline 2.2 & The quality & 4.00 & 1.00 & High \\
\hline 2.3 & The suitability for usage & 4.33 & 1.15 & Highest \\
\hline 2.4 & The suitability for the seat cushion product & 4.66 & 0.57 & High \\
\hline & Total & 4.33 & 0.82 & High \\
\hline \multicolumn{5}{|c|}{ 3. The marketing } \\
\hline 3.1 & The product could be an interesting attraction from consumer & 4.33 & 0.57 & High \\
\hline 3.2 & The product could be promoted sales by themselves & 4.00 & 1.00 & High \\
\hline 3.3 & The product could be convey to identity & 5.00 & 0.00 & Medium \\
\hline 3.4 & The appropriateness of cost and size & 4.00 & 1.00 & Medium \\
\hline \multicolumn{2}{|r|}{ Total } & 4.33 & 0.64 & High \\
\hline
\end{tabular}

According to Table 3, the assessment result form 3 experts in the design field towards the seat cushion product in terms of beauty as well as the composition of pattern revealed that their opinion affected in terms of color and pattern was a high level with appropriate to conduct the pattern for usability, in terms of function of the usability of seat cushion product found their opinion affected in terms of durability, in terms of quality, in terms of suitability size for usage and in terms of suitability for the seat cushion product were a high level, their opinion affected in terms of market found that in terms of the product could be an interesting attraction from the consumer and the product could be promoted sales by themselves were a high level.

\section{Discussion of Research Result}

The pattern design with inspiration from the white champaka due to implication about "the kudos life, work promoted" also represented feminine characteristic women since these flowers had used as the accessories for women, for example, using a white champaka flower likes a barrette, tie it up at the ended hairs as a result of the aroma which it could be used instead of the perfume. The white champaka flowers were drawn aflutter as though naturally in order to they are moving by a researcher, accordingly, a researcher had conducted the repeating and rhythm technique to organize and affect the pattern with interesting. Pastel yellow was used as the background, selected blue color and dark yellow for the representative the white champaka, 80 percentages of the cool color affected to comfortable feeling and 20 percentages of red color from warm color as a red line had shown the petals were blooming. Furthermore, a cushion seat product has developed which, inspired by the a white champaka either, however, within the cushion seat contains the herbal incense such as Thao En On which had been used to treat about blood health, help heal internal organ pained, the turmeric had been used to reduce inflammation, kaffir lime rinds of peel have the aroma oil that helps the dizzy, the citronella grass had been reduced pain and aches, help heal the pain as well as the beriberi, the eucalyptus leaf had been used for skin care treatment, help heal skin disease and help lower blood pressure, the tamarind leaf had been helped heal the itch 
and skin care treatment, the common salt had been used for dehydration, help the medicine permeate the skin conveniently, the menthol had been used for pleasing scent, a heart treatment, heal blisters, therefore the aroma from the herbs had been helped to reduce stress. According to Chandhasa, R. (2017) described, the souvenir which conveys the story of each place is greatly important. Human beings are social animals who intercommunicate in one way or another through a period of time until they have a deep connection, satisfaction, social interaction among humans or attachment between humans and surroundings, such as locations, circumstances, objects, etc., which are conducive to memory, as well as recalling. Although the communicating activities end, the exhilaration is still desired to be continued, even the time passes, or because of distance which effectuates meeting, familiarity, taste and behavior similarity, necessity of interdependence, support among a group, action involving reward as a result of affection, and the like. These factors motivate creating souvenirs which people like to give to each other. Notably, human beings' brain consciously registers stories, experiences, people, as well as other things around them in a memory form. The massive accumulated data in head may lead to the confusion which is hard to organize; moreover, the remembrance may ultimately fade away as time passes. Hence, humans try to discover the ways to stimulate memory of the related stories by producing media and reminders in order to persuade people to recognize them consistently. In another word, the media and reminders are created to activate memory. According to Soodsang, N. (2016) described, it can be promote their collective activities in marketing promotion for raised income of their groups, thus giving the sense of pride in their own products and also more choices for consumers. It provided guidelines to agriculturists in the distribution of their rice products. They can exchange and share marketing business knowledge, and ensure that products quality meet the quality standards.

\section{Acknowledgments}

This research was supported by Suan Sunandha Rajabhat University.

\section{Reference}

Ausaranon, M., et al. (1988). Encyclopedia of Thai Northern District Folk Commodity in the Pass. Bangkok: Amarin Printing.

Bunwong, N. (2002). The Principle of Design. Bangkok: Chulalongkorn University Printing House.

Chandhasa, R. (2017).Thai Traditional Hanging Garland Decoration to the Pattern Design Adapted on Suan Sunandha Rajabhat University Souvenir. Asian Social Science, 13(7). 131-141. https://doi.org/10.5539/ass.v13n7p131

Chansoon, S. (1991). Folk Wisdom. In the National Culture Committee. The Office of Folk Wisdom Knowledge Seminar.

Chareonrath, O. (2003). Sufficiency Economy under Social changes of Thailand. Bangkok: Pimdee Press.

Chuenrungraung, C. (1994). Miscellaneous Article Tourism(Vol.2). Chiang Mai: Chiang Mai University.

Leesakul, W. (1989). The weaving Stuff in Thailand. Bangkok: Odeon Store Press.

Leesakul, W. (2003). Folk Art. Bangkok: Amarin Printing.

Linasen, S. (1983). Alphabet Design. Bangkok: Odeon Store Press.

Ministry of Culture. (2009). The National Culture Plan Template. Bangkok: Bureau of Policy and Strategy Ministry of Culture.

Ministry of Tourism and Sports. (2011). The National Tourism Development Plan: 2012-2016.Bangkok:National Tourism Policy.

Payomyam, S. (1994). Printing Process. Bangkok: Odeon Store Press.

Peters, S. (2005). Graphic Design. Bangkok: Teaching Documentation of King Mongkut's Institute of Technology Ladkrabang.

Samut Sakhon Principal Office. (2008).Overall Operation Report the administration of Samut Sakhon province. Retrieved from http://www.maeklongtoday.com/amphawa/amphawa_1.php

Sikkabandit, S. (1984). Alphabet Design. Bangkok: Odeon Store press.

Soodsang, N. (2016). A Model Development of Thai Rice Label and Package for Heath Conscious Group of Consumers on Social Media. Asian Social Science, 12(6), 1-6. https://doi.org/10.5539/ass.v12n6p217

Srikantrabud, A. (2007). Graphic Design. Bangkok: Viscom Center Co, Ltd. 
Sudsung, N. (2000). Industrial Design and Product Development Industry. Bangkok: Textbooks and document Faculty of Industrial Education and Technology King Mongkut's Institute of Technology Ladkrabang.

Sudsung, N. (2003). The Industrial Product Design. Bangkok: Odeon Store Press.

Sudsung, N. (2004). The Industrial Product Design Research. Bangkok: Odeon Store Press.

Vejchacheewa, A. (Former Prime Minister). (2009). Retrieved from http:// www. pm. go.th /blog/3233

Wasee, P. (1991). The Study of Exotic teas with the Wisdom of Local National Cultural Committee. Seminar on Wisdom, Operation culture and Rural development. Bangkok: Amarin Printing Group.

\section{Copyrights}

Copyright for this article is retained by the author(s), with first publication rights granted to the journal.

This is an open-access article distributed under the terms and conditions of the Creative Commons Attribution license (http://creativecommons.org/licenses/by/4.0/). 